\title{
Errors and Obsolete Elements in Assigned Library of Congress Subject Headings: Implications for Subject Cataloging and Subject Authority Control
}

\section{Lois Mai Chan and Diane Vizine-Goetz}

\begin{abstract}
An analysis of a sample of 9,442 headings assigned by the Library of Congress $(L C)$ to bibliographic records disclosed two types of invalid headings: those that were erroneous and those that were obsolete. Each type revealed recurring patterns. Errors and obsolete elements occurring in assigned headings involve MAchine Readable Cataloging (MARC) coding, terminology in main headings and subdivisions, application of subdivisions, and in mechanical elements such as punctuation and capitalization. Different headings (e.g., personal name, corporate name, topical, etc.) display different patterns as well as predominance of errors and obsoleteness. Although the overall error rate is low, an awareness and understanding of patterns of errors and obsolescence in subject heading strings should contribute to improvement in subject heading assignment and subject authority control.
\end{abstract}

\section{NaTURE, SCOPE, AND HYPOTHESES}

Two factors contribute to effectiveness in subject retrieval: close match between indexing terms and document content; and predictability and consistency of access points. In an earlier investigation, Svenonius and McGarry (1993) studied the question of appropriateness of subject heading assignment and their findings have been reported. The other important factor is the consistency and accuracy in the forms of the headings. In authority control, a major goal is to achieve consis- tency and accuracy by adhering to standards and guidelines. In the case of subject authority control, these include Library of Congress Subject Headings (LCSH), Subject Cataloging Manual: Subject Headings, USMARC Formats, and AngloAmerican Cataloguing Rules, second edition, 1988 revision (AACR2R).

Because of the use of free-floating subdivisions and headings taken from name authority records, catalogers seldom derive complete subject headings from $L C S H$. Only a small percentage of subject headings assigned to bibliographic re-

Lois Mai Chan is Professor, School of Library and Information Science, College of Communications and Information Studies, Lexington, Kentucky. DIANE VIZiNE-GoETZ is Consulting Research Scientist, Office of Research, OCLC, Dublin, Ohio. This project was supported by a research grant from OCLC Online Computer Library Center, Inc. Manuscript received June 19, 1997; accepted for publication August 26, 1997. 
cords come directly from $L C S H$. Previous studies on exact matches include those reported by Ludy (1985), Frost and Dede (1988), and Drabenstott and VizineGoetz (1994). Because of the need to synthesize heading strings in subject cataloging, errors do occur. Furthermore, constant changes in subject headings and heading assignment policies result in many headings becoming obsolete. Important operations in subject authority control include detecting and correcting errors and maintaining currency.

In an earlier study, Chan and VizineGoetz (1997) explored the feasibility of automatically generating a subject validation file with complete strings but few errors and obsolete elements from LC-assigned subject headings appearing in bibliographic records. They included an analysis of the distribution and density of subject headings by frequency of use and by type of headings as well as a calculation of the rate of errors and obsolete elements in subject headings that have been used at least twice each in the LC MARC (Machine Readable Cataloging) database.

In the current study, we analyzed the nature and patterns of incorrect and obsolete elements among subject headings assigned by LC. Although errors among these headings occur at a relatively low rate, an awareness of the nature of errors can help catalogers avoid or minimize similar errors in the future. An understanding of the recurring patterns of errors and obsolete elements can also lead to improved mechanisms for identifying and correcting errors and updating obsolete headings automatically.

\section{METHOD}

Details of the experimental methodology used in this study have been reported earlier (Chan and Vizine-Goetz 1996). They are briefly summarized below.

\section{STUDY SAMPLE}

The Subject Heading Corrections database, developed to correct subject heading errors in the OCLC Online Computer Library Center, Inc. Online Union Cata- $\log ($ OLUC), was the source of headings for this project. The database contains an entry for each unique subject heading used in bibliographic records loaded into the OCLC system through November 1992 (more than 4 million headings). A $1 \%$ sample, consisting of 20,743 headings among those assigned by LC, was extracted from the database for further processing and examination.

An early operation on the study sample was to rank headings by frequency of use. This ranking, reported earlier (Chan and Vizine-Goetz 1997), showed that 5,970 headings had each been used twice or more, and 14,503 had each been used only once. Because of the large size of the latter group (the frequency-1 group), it was decided to analyze a subset that would represent a cross section of this group; this was compiled by taking all the headings in the frequency-1 group beginning with the letters A, F, M, T, and Z, which resulted in a frequency-1 study sample of 3,472 headings. This sampling method was employed because the total $1 \%$ sample was originally taken randomly from the entire universe of assigned subject headings; and it was decided to draw the sub-sample of headings with a frequency of 1 from a cross section of the original $1 \%$ sample by taking all headings beginning with specific letters that were spread across the alphabet from A to $\mathrm{Z}$. Thus, the study sample used as the basis for analyzing errors and obsolete elements in this study consisted of 5,970 headings with a frequency of use of 2 or greater, and 3,472 headings with a frequency of 1 , resulting in a total sample of 9,442 headings.

\section{Data Analysis}

\section{Evaluation of Headings}

The headings were categorized according to the following types: personal name headings (MARC 600), corporate name headings (MARC 610), headings for meetings (MARC 611), uniform titles (MARC 630), topical and form headings (MARC 650), and geographic name headings (MARC 651). Table 1 shows a distribution of the sample headings by frequency of use and by type of heading. 
TABLE 1

Distribution of Sample Headings by Tag

\begin{tabular}{lccrrrrrr}
\hline \hline & MARC & MARC & MARC & MARC & MARC & MARC & \\
Frequency & 600 & 610 & 611 & 630 & 650 & 651 & TOTAL & Cum. Ct. \\
\hline 500 & & & & & 2 & 1 & 3 & 3 \\
$401-500$ & & & & & 3 & & 3 & 6 \\
$301-400$ & 1 & & & & 3 & & 4 & 10 \\
$201-300$ & & & & & 8 & 2 & 10 & 20 \\
$101-200$ & & & & & 20 & 8 & 28 & 48 \\
$51-100$ & 1 & & & & 59 & 14 & 74 & 122 \\
$46-50$ & & & & & 15 & 2 & 17 & 139 \\
$41-45$ & 2 & & & & 17 & 3 & 22 & 161 \\
$36-40$ & & & & & 23 & 5 & 28 & 189 \\
$31-35$ & 1 & & & & 27 & 7 & 35 & 224 \\
$26-30$ & 1 & 1 & & & 38 & 7 & 47 & 271 \\
$21-25$ & 6 & 1 & & 1 & 62 & 12 & 82 & 353 \\
$16-20$ & 1 & 1 & & 2 & 89 & 22 & 115 & 468 \\
$11-15$ & 14 & 5 & & & 184 & 43 & 246 & 714 \\
$6-10$ & 42 & 11 & & 7 & 563 & 169 & 792 & 1,506 \\
$3-5$ & 144 & 59 & & 17 & 1,311 & 345 & 1,876 & 3,382 \\
2 & 250 & 103 & & 12 & 1,809 & 414 & 2,588 & 4,970 \\
10 & 375 & 182 & 5 & 23 & 2,424 & 463 & 3,472 & 9,442 \\
TOTAL & 838 & 363 & 5 & 62 & 6,657 & 1,517 & 9,442 & \\
\hline
\end{tabular}

"Based on $23.93 \%$ of sample

Each of the 9,442 headings in the study sample was checked for correct MARC tagging, terminology, syntax, spelling, punctuation, capitalization, etc. according to the standards and/or authority files listed below:

- USMARC Formats for authority data and for bibliographic data

- Library of Congress Subject Headings $(\mathrm{LCSH})$ (both the print version and the LCXR (SUBJECTS) file in LOCIS)

- Authority records in the NAMES (name authority) file in LOCIS (Library of Congress Information System)

- Free-Floating Subdivisions: An Alphabetical Index

- Subject Cataloging Manual: Subject Headings

- Revised Library of Congress Subject Headings

- AACR2R
Figures 1-5 illustrate the procedures of analyzing headings for errors and obsolete elements. In figure 1, the heading is obsolete because it carries the defunct subdivision Addresses, essays, lectures. In figure 2, the heading is incorrect. The subdivision should be Rules and practice. In figures 3 and 4 , the headings are valid. In figure 5 , the use of the subdivision History is incorrect; it may not follow the subdivision Foreign economic relations.

Types of Errons and Obsolescence

After verification, headings that were found to be invalid were categorized as either incorrect or obsolete. Incorrect headings were headings that contain one or more errors. Types of errors included those in coding (MARC tags or subfield codes), in main headings (errors in form, entry element, terminology, or syntax; or, in the case of free-floating phrases, im- 
600 Petrarca, Francesco, \$d 1304-1374 \$x Criticism and interpretation \$x Addresses, essays, lectures

$\begin{array}{ll}\text { Elementin heading } & \text { Authority tools } \\ 600, \$ \mathrm{~d}, \$ \mathrm{x}, \$ \mathrm{x} & \text { USMARC Formats } \\ \text { Petrarca, Francesco, \$d 1304-1374 } & \text { Name authority file } \\ \text { Criticism and interpretation \} } &{/ \text { Free-Floating Subdivisions }} \\{\text { Addresses, essays, lectures / }} &{\backslash \text { Subject Cataloging Manual }}\end{array}$

Figure 1. Personal Name Heading Analysis.

610 Florida. \$b Legislature. \$b House of Representatives \$x Rules of practice

$\begin{array}{ll}\text { Element in heading } & \text { Authority tools } \\ 610, \$ \mathrm{~b}, \$ \mathrm{~b}, \$ \mathrm{x} & \text { USMARC Formats } \\ \begin{array}{l}\text { Florida. \$b Legislature. \$b } \\ \text { House of Representatives }\end{array} & \text { Name authority file } \\ \text { Rules of practice } & / \text { Free-Floating Subdivisions } \\ & \backslash \text { Subject Cataloging Mamual }\end{array}$

Figure 2. Corporate Name Heading Analysis.

630 Bible. \$p O.T. \$p Habakkuk \$x Criticism, interpretation, etc.

$\begin{array}{ll}\text { Elementin heading } & \text { Authority tools } \\ 630, \$ \mathrm{p}, \$ \mathrm{p}, \$ \mathrm{x} & \text { USMARC Formats } \\ \text { Bible. } \$ \mathrm{p} \text { O.T. } \$ \mathrm{p} \text { Habakkuk } & \text { Name authority file } \\ \text { Criticism, interpretation, etc. } & / \text { Free-Floating Subdivisions } \\ & \backslash \text { Subject Cataloging Manual }\end{array}$

Figure 3. Uniform Title Heading Analysis.

650 Housing $\$$ z Australia $\$ \mathrm{z}$ Western Australia $\$ \mathrm{x}$ Statistics $\$ \mathrm{x}$ Periodicals

$\begin{array}{ll}\text { Elementin heading } & \text { Authority tools } \\ 650, \$ \mathrm{z}, \$ \mathrm{z}, \$ \mathrm{x}, \$ \mathrm{x} & \text { USMARC Formats } \\ \text { Housing } & \text { LCSH } \\ \text { Australia } & / \mathrm{Name} \text { authority file } \\ \text { Western Australia/ } & \backslash \text { LCSH } \\ \text { Statistics } & / \text { Free-Floating Subdivisions } \\ \text { Periodicals } & \backslash \text { Subject Cataloging Manual } \\ \text { <Indirect subdivision> } & \text { Subject Cataloging Manual }\end{array}$

Figure 4. Topical Heading Analysis.

properly synthesized main headings), in subdivisions (including incorrect forms of subdivision and improper combinations of either Main Heading-Subdivision or
-Subdivision-Subdivision), and in mechanical elements such as punctuation, capitalization, spacing, etc. Obsolete headings were headings that were not 
651 Latin America \$x Foreign economic relations \$z Great Britain \$x History

Element in heading

$651, \$ x, \$ z, \$ x$

Latin America

Foreign economic relations

Great Britain

History
Authority tools

USMARC Formats

LCSH

/ Free-Floating Subdivisions

$\backslash$ Subject Cataloging Manual

LCSH

Subject Cataloging Manual

Figure 5. Geographic Name Heading Analysis.

valid at the time the sample was generated but matched earlier name headings, or were valid according to previous editions (15th or earlier) of $L C S H$ or previous editions (4th or earlier) of Free-Floating Subdivisions.

Many invalid headings, particularly those with lower frequencies of use, contain personal, corporate, or geographic names, meeting names, and uniform titles that do not have corresponding name authority records in either the NAMES file or $L C S H$. These constitute a special type of obsolete heading, because current policy requires that each name used in or as a subject heading (except those formed by free-floating phrases) be established in the authority files. In fact, some of these unverifiable names may have corresponding authority records in the old card file kept at LC. However, to be used as authorized names in cataloging new items, it is LC policy that these names be re-evaluated and re-established in the MARC authority files. Therefore, while the headings may well be valid or correct according to AACR2R, the lack of current authority records means they cannot be considered authorized or used as models for validating assigned headings or for formulating new headings until established in the authority files. As a result, in this study the unverified name headings are considered invalid for all practical purposes.

Because AACR2R places primary emphasis on the way the names appear in the works as the basis for determining the forms of name headings, it would be impossible to determine with certainty the correct forms of the headings without hav- ing the items in hand. Therefore, no attempt was made in this study to evaluate the validity of these name headings in the same way the topical and nonjurisdictional headings were verified. Nevertheless, it was felt that because of the special nature of their invalidity these headings were worth reporting and therefore have been placed in a separate category in this study. The statistics regarding these headings are presented in the tables for obsolete headings. The reason for placing these headings with obsolete headings is that earlier LCSH editions included many more categories of unprinted headings (i.e., headings that were allowed to be used in cataloging records without being established in the list). Such headings included not only personal and corporate names but also names of chemicals, minerals, geographic features, etc. This practice is now obsolete; except for a small number of free-floating phrase headings and musical headings formed according to established citation formulae, all valid topical and name headings now have corresponding records in the name or subject authority file.

Types of obsolete elements include obsolete coding (MARC tags or subfield codes), obsolete main headings, obsolete subdivisions (including subdivisions in obsolete forms and obsolete Main Heading-Subdivision or -Subdivision-Subdivision combinations), obsolete punctuation, capitalization, etc., and unverifiable names.

A heading containing more than one type of invalid element was placed in the first category according to the order listed 
TABLE 2

Distribution of InValid Headings By Heading Type

\begin{tabular}{lccccccc}
\hline & $\begin{array}{c}\text { No. of } \\
\text { Sample } \\
\text { Tag }\end{array}$ & $\begin{array}{c}\text { Incorrect } \\
\text { Headings }\end{array}$ & $\begin{array}{c}\text { Incorrect } \\
\text { Headings - } \\
\%\end{array}$ & $\begin{array}{c}\text { Obsolete } \\
\text { Headings }\end{array}$ & $\begin{array}{c}\text { Obsolete } \\
\text { Headings - } \\
\%\end{array}$ & $\begin{array}{c}\text { Total No. } \\
\text { of Invalid } \\
\text { Headings }\end{array}$ & $\begin{array}{c}\text { Total } \\
\text { Invalid } \\
\text { Headings - } \\
\%\end{array}$ \\
\hline 600 & 838 & 33 & 3.94 & 73 & 8.71 & 106 & 12.65 \\
610 & 363 & 39 & 10.74 & 52 & 14.33 & 91 & 25.07 \\
611 & 5 & 1 & 20.00 & 2 & 40.00 & 3 & 60.00 \\
630 & 62 & 8 & 12.90 & 13 & 20.97 & 21 & 33.87 \\
650 & 6,657 & 168 & 2.52 & 277 & 4.16 & 445 & 6.68 \\
651 & 1,517 & 57 & 3.76 & 142 & 9.36 & 199 & 13.12 \\
TOTAL & 9,442 & 306 & 3.24 & 559 & 5.92 & 865 & 9.16 \\
\hline
\end{tabular}

above: incorrect, obsolete. Thus, a heading that is both incorrect and obsolete was placed in the category of incorrect headings; a heading containing obsolete elements in both the main heading and a subdivision was placed in the category of obsolete main headings. Headings containing more than one error or obsolete element were counted once each.

\section{RESUlts}

Statistical details of the results have been reported earlier (Chan and Vizine-Goetz 1996). They are presented briefly here in order to provide a context for the analysis and discussion of invalid headings presented in this paper.

\section{Distribution of INVALID HeAdings By TAG}

Data showing the distribution of invalid headings by tag, i.e., type of heading, are presented in table 2. The combined rate of incorrect and obsolete headings, including all types of headings in all frequencies of use, was $9.16 \%$ (865 invalid headings out of a sample of 9,442 headings). The percentage of invalid headings by type of heading, in descending order, is: MARC 611 (60.00\%), MARC 630 (33.87\%), MARC 610 (25.07\%), MARC $651(13.12 \%)$, MARC $600(12.65 \%)$, and MARC 650 (6.68\%).

The rate of incorrect headings, including all types of headings in all frequencies of use, is $3.24 \%$ (306 incorrect headings out of a sample of 9,442 headings). The percentage of incorrect headings by type of heading, in descending order, is: MARC $611 \quad(20.00 \%)$, MARC 630 (12.90\%), MARC $610(10.74 \%)$, MARC 600 (3.94\%), MARC 651 (3.76\%), and MARC $650(2.52 \%)$. The rate of obsolete headings, including all types of headings in all frequencies of use, is $5.92 \%$ (559 obsolete headings out of a sample of 9,442 headings). The percentage of obsolete headings by type of heading, in descending order, is: MARC 611 (40.00\%), MARC $630 \quad(20.97 \%)$, MARC 610 (14.33\%), MARC 651 (9.36\%), MARC $600(8.71 \%)$, and MARC $650(4.16 \%)$. The high percentage of invalid headings among headings for meetings (MARC 611) might be due to the small size of the sample (a total of 5).

\section{PATTERNS OF INCORRECT HEADINGS}

Table 3 shows the distribution of the 306 incorrect headings by type of heading and type of error. Overall, the largest number of errors were found in the main heading and in subdivisions (with 109 each), followed by errors in coding (73), and errors in punctuation, capitalization, etc. (15).

The patterns of occurrence of different types of errors in terms of various types of headings are summarized below. Within each type of heading, types of errors are listed in descending order of occurrence:

- 33 incorrect personal name headings 
TABLE 3

INCORRECT HEADINGS BY

TyPE OF HEADING AND TYPE OF ERROR

\begin{tabular}{|c|c|c|c|c|c|c|c|c|c|c|c|}
\hline 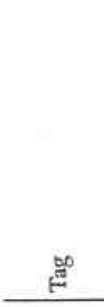 & $\begin{array}{l}\text {.0 } \\
\text { 吾 } \\
0\end{array}$ & 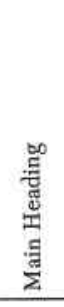 & 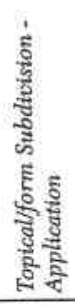 & 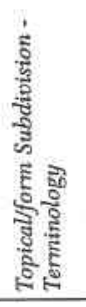 & 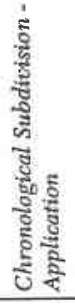 & 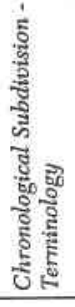 & 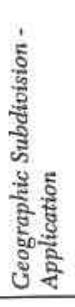 & 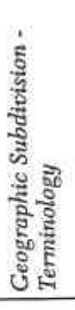 & 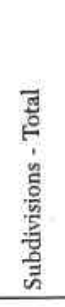 & 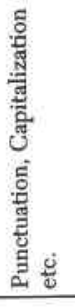 & 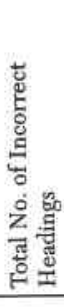 \\
\hline 600 & 4 & 23 & 1 & & & & & & 1 & 5 & 33 \\
\hline 610 & 14 & 14 & 4 & 2 & & & 2 & & 8 & 3 & 39 \\
\hline 611 & & 1 & & & & & & & & & 1 \\
\hline 630 & 4 & 3 & & 1 & & & & & 1 & & 8 \\
\hline 650 & 43 & 45 & 26 & 6 & 5 & & 22 & 17 & 76 & 4 & 168 \\
\hline 651 & 8 & 23 & 13 & 3 & 1 & 4 & 2 & & 23 & 3 & 57 \\
\hline TOTAL & 73 & 109 & 44 & 12 & 6 & 4 & 26 & 17 & 109 & 15 & 306 \\
\hline
\end{tabular}

with errors in main headings (23), in punctuation, capitalization, etc. (5), in coding (4), and in subdivision (1)

- 39 corporate name headings, with errors in main headings (14), in coding (14), in subdivisions (8), and in punctuation, capitalization, etc. (3)

- 1 incorrect heading for meetings, with an error in the main heading

- 8 incorrect uniform title headings, with errors in coding (4), in main headings (3) and in subdivision (1)

- 168 incorrect topical headings, with errors in subdivisions (76), in main headings (45), in coding (43), and in punctuation, capitalization, etc.(4)

- 57 incorrect geographic name headings, with errors in main headings (23), in subdivisions (23), in coding (8), and in punctuation, capitalization, etc. (3)

\section{Patterns of Obsolete Headings}

Table 4 shows the distribution of the 559 obsolete headings by category of heading and type of obsolete element. Overall, the largest number of obsolete elements occur in subdivisions (289), followed by unverified names (135), obsolete elements in the main heading (117), obsolete punctuation, capitalization, etc. (17), and obsolete coding (1).

The patterns of occurrence of different types of obsolete elements in terms of various types of headings are summarized below. Within each type of heading, types of obsolete elements are listed in descending order of occurrence:

- 73 obsolete personal name headings, with unverified names (44), obsolete elements in the main heading (14), obsolete elements in subdivisions (13), and obsolete punctuation, capitalization, etc. (2)

- 52 obsolete corporate name headings, with unverified names (30), obsolete elements in subdivisions (11), obsolete elements in main headings (9), obsolete punctuation, capitalization, etc. (1), and obsolete coding (1)

- 2 obsolete headings for meetings, with obsolete elements in main headings in both cases

- 13 obsolete uniform title headings, with obsolete elements in subdivisions (6), unverified uniform titles (5), and obsolete elements in main headings (2)

- 277 obsolete topical headings, with 


\begin{tabular}{|c|c|c|c|c|c|c|c|c|c|c|c|c|}
\hline 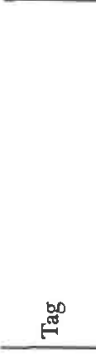 & 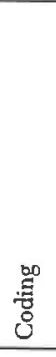 & 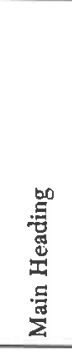 & 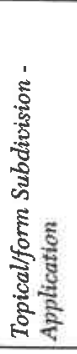 & 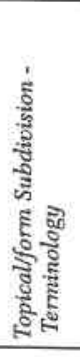 & 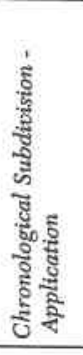 & 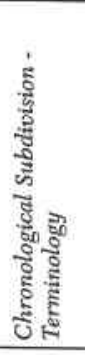 & 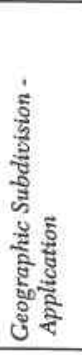 & 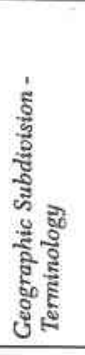 & 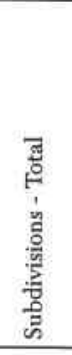 & 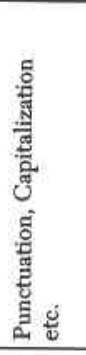 & 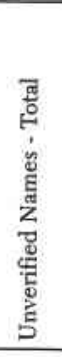 & 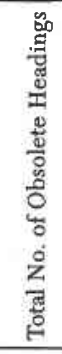 \\
\hline 600 & & 14 & 12 & 1 & & & & & 13 & 2 & 44 & 73 \\
\hline 610 & 1 & 9 & 10 & & & & & 1 & 11 & 1 & 30 & 52 \\
\hline 611 & & 2 & & & & & & & & & & 2 \\
\hline 630 & & 2 & 6 & & & & & & 6 & & 5 & 13 \\
\hline 650 & & 41 & 33 & 12 & & 2 & 41 & 127 & 215 & 8 & 13 & 277 \\
\hline 651 & & 49 & 31 & 3 & 1 & 4 & 2 & 3 & 44 & 6 & 43 & 142 \\
\hline TOTAL & 1 & 117 & 92 & 16 & 1 & 6 & 43 & 131 & 289 & 17 & 135 & 559 \\
\hline
\end{tabular}

obsolete elements in subdivisions (215), obsolete elements in main headings (41), unverified names (13), and obsolete punctuation, capitalization, etc. (8)

- 142 obsolete geographic name headings, with obsolete elements in main headings (49), obsolete elements in subdivisions (44), unverified names (43), and obsolete punctuation, capitalization, etc. (6).

\section{Patterns of InVAlid Subdivisions}

Tables 5 and 6 display data regarding invalid subdivisions only. In table 5 , columns A-E present data regarding topicalform subdivisions (subfield $\mathrm{x}$ ), columns F-J regarding chronological subdivisions (subfield y), and columns K-O regarding geographic subdivisions (subfield z). Within each type of subdivision, invalid elements are divided into incorrect or obsolete subdivisions, and each is further divided into application and terminology or syntax. "Application" refers to incorrect or improper combination of main headings and subdivisions, and "terminology or syntax" refers to incorrect or obsolete words and phrases or grammatical structure.
Taken together, 164 of the invalid headings involve topical/form subdivisions (subfield $x$ ). There appear to be few problems with chronological subdivisions (subfield y); only 17 invalid headings involve period subdivisions. Two hundred and seventeen, or more than half, of the 398 invalid headings pertain to geographic subdivisions (subfield z).

Among personal name headings and uniform title headings, all invalid subdivisions involve topical/form subdivisions. A possible explanation is that these types of headings are rarely subdivided chronologically or geographically. No invalid subdivision was found among headings for meetings. For corporate name headings, invalid elements occur in topical/form subdivisions (subfield $\mathrm{x}$ ) ( 16 of 19 , or $84 \%$ ) and geographic subdivisions (subfield $\mathrm{z}$ ) ( 3 of 19 , or $16 \%$ ). For topical headings, invalid subdivisions involve all three types of subdivisions, with the majority (207 of 291 , or $71 \%$ ) being geographic subdivisions (subfield z), followed by topi$\mathrm{cal} /$ form subdivisions (subfield $\mathrm{x}$ ) (77 of 291 , or $27 \%$ ) and chronological subdivi sions (subfield y) ( 7 of 291 , or $2 \%$ ). For geographic headings, the majority of invalid subdivisions involve topical/form subdivi- 


\section{TABLE 5}

INVALID SUBDIVISIONS BY TYPE OF HEADING

\begin{tabular}{|c|c|c|c|c|c|c|c|c|c|c|c|c|c|c|c|c|}
\hline \multirow[b]{4}{*}{ 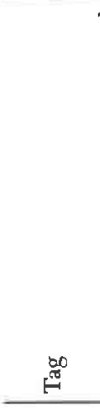 } & \multicolumn{4}{|c|}{ TOPICAL/FORM (\$x) } & & \multicolumn{5}{|c|}{ CHRONOLOGICAL (\$y) } & \multicolumn{4}{|c|}{ GEOGRAPHIC (\$z) } & \multirow[b]{3}{*}{$\mathrm{O}$} & \multirow[b]{3}{*}{$\mathbf{P}$} \\
\hline & \multicolumn{2}{|c|}{ Incorrect } & \multicolumn{2}{|c|}{ Obsolete } & \multirow[b]{2}{*}{$\mathbf{E}$} & \multicolumn{2}{|c|}{ Incorrect } & \multicolumn{2}{|c|}{ Obsolete } & \multirow[b]{2}{*}{$\mathrm{J}$} & \multicolumn{2}{|c|}{ Incorrect } & \multicolumn{2}{|c|}{ Obsolete } & & \\
\hline & A & B & $\mathrm{C}$ & $\mathrm{D}$ & & $\mathbf{F}$ & G & $\mathrm{H}$ & I & & K & $\mathbf{L}$ & M & $\mathrm{N}$ & & \\
\hline & 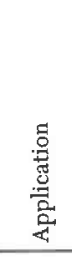 & 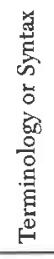 & 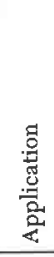 & 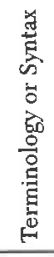 & 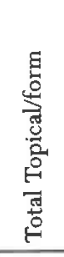 & 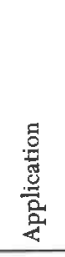 & 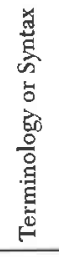 & $\frac{\text { है }}{\frac{\tilde{E}}{\tilde{E}}}$ & 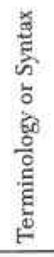 & 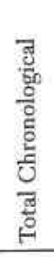 & 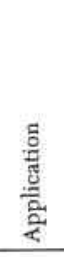 & 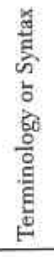 & 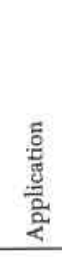 & 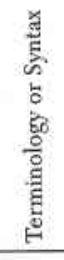 & 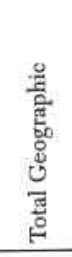 & 항 \\
\hline 600 & 1 & & 12 & 1 & 14 & & & & & & & & & & & 14 \\
\hline 610 & 4 & 2 & 10 & & 16 & & & & & & 2 & & & 1 & 3 & 19 \\
\hline 611 & & & & & & & & & & & & & & & & \\
\hline 630 & & 1 & 6 & & 7 & & & & & & & & & & & 7 \\
\hline 650 & 26 & 6 & 33 & 12 & 77 & 5 & & & 2 & 7 & 22 & 17 & 41 & 127 & 207 & 291 \\
\hline 651 & 13 & 3 & 31 & 3 & 50 & 1 & 4 & 1 & 4 & 10 & 2 & & 2 & 3 & 7 & 67 \\
\hline TOTAL & 44 & 12 & 92 & 16 & 164 & 6 & 4 & 1 & 6 & 17 & 26 & 17 & 43 & 131 & 217 & 398 \\
\hline
\end{tabular}

sions (subfield $x$ ) ( 50 of 67 , or $75 \%$ ), followed by chronological subdivisions (subfield y) (10 of 67 , or $15 \%$ ), and geographic subdivisions (subfield z) ( 7 of 67 , or $10 \%$ ).

\section{Application vs. Terminology}

Table 6 shows a summary of errors and obsolete elements in terms of application and form (terminology or syntax) of subdivisions. In all, $212(53 \%)$ of the 398 invalid subdivisions involve application, and 186 (47\%) pertain to terminology or syntax.

Among the 164 invalid topical/form subdivisions, 136 (83\%), an overwhelming majority, have to do with application, and $28(17 \%)$ pertain to terminology or syntax. Forty-four of the 136 invalid applications represent improper combination of Main Heading - Subdivision or - Subdivision-Subdivision, and 92 reflect obsolete practice. Among the 28 topical/form subdivisions with invalid terms or syntax, 12 are errors, and 16 reflect obsolete terminology or syntax.

Among the 17 invalid chronological subdivisions, $7(41 \%)$ have to do with application and $10(59 \%)$ with terminology or syntax. Six of the 7 invalid applications show incorrect combination of Main Heading-Subdivision or -Subdivision-Subdivision, and only 1 reflects obsolete practice. Among the 10 invalid terms, 4 are errors and 6 reflect obsolete dates or terms.

Among the 217 invalid geographic subdivisions, $69(32 \%)$ involve invalid application, and $148(68 \%)$ contain invalid forms of geographic names. Twenty-six of the 69 invalid applications show incorrect combination of Main Heading-Subdivision or -Subdivision-Subdivision, and 43 reflect obsolete geographic subdivision practice. Among the 148 invalid geographic names, 17 are errors and 131 reflect obsolete geographic names.

\section{ANalyses of InValid Headings}

In the following section, we present and analyze the nature of errors and obsolete elements within each category of headings:

\section{Personal Name Headings}

\section{INCORRECT HEADINGS}

As shown in table 3 , a total of 33 incorrect 


\section{TABLE 6}

INVALID SUBDIVISIONS: APPLICATION VS. TERMINOLOGY

\begin{tabular}{|c|c|c|c|c|c|c|c|c|c|c|}
\hline \multirow[b]{2}{*}{$\stackrel{+\infty}{\oplus}$} & \multicolumn{3}{|c|}{ TOPICAL/FORM (\$x) } & \multicolumn{3}{|c|}{ CHRONOLOGICAL (\$y) } & \multicolumn{3}{|c|}{ GEOGRAPHIC (\$z) } & \\
\hline & 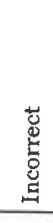 & 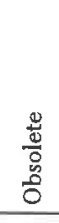 & 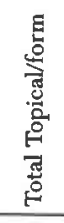 & $\begin{array}{l}\tilde{U} \\
\mathbb{E} \\
\stackrel{0}{0} \\
\Xi \\
\end{array}$ & 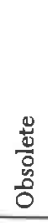 & 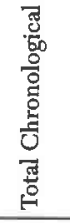 & 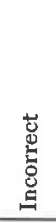 & 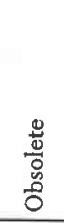 & 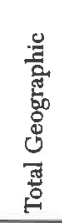 & 莫 \\
\hline Application & 44 & 92 & 136 & 6 & 1 & 7 & 26 & 43 & 69 & 212 \\
\hline Terminology & 12 & 16 & 28 & 4 & 6 & 10 & 17 & 131 & 148 & 186 \\
\hline TOTAL & 56 & 108 & 164 & 10 & 7 & 17 & 43 & 174 & 217 & 398 \\
\hline
\end{tabular}

personal name headings were identified. Incidentally, all of these show a frequency of use of 1 . Types of errors, in descending order by the number of occurrences, are:

1. Errors in main headings (23 occurrences). Kinds of errors include incorrect or missing dates, incorrect form of headings, incorrect entry elements, and incorrect uniform titles (see figure 6).

2. Errors in punctuation, capitalization, etc. (5 occurrences). Mechanical errors (i.e., incorrect punctuation, capitalization, etc.) among personal name headings include missing punctuation marks, incorrect punctuation, and incorrect capitalization (see figure 7).

3. Errors in coding (4 occurrences). Errors in coding appear in the form of missing codes, extraneous codes, or incorrect codes (see figure 8).

4. Error in the subdivision (1 occurrence). Only 1 error in the subdivision was identified; it involves subfield $x$ (see figure 9).

\section{Obsolete Headings}

As shown in table 4, a total of 73 obsolete personal name headings were identified. Types of obsolete elements, in descending order by the number of occurrences, are:

1. Unverified names in main headings (44 occurrences). The largest number (44 of 73 , or over $60 \%$ ) of obso lete personal name headings contain an unverified personal name or uni- form title in the main heading. Thirty-five of the 44 , or close to $80 \%$, show a frequency of use of 1 . The majority of the 44 contain unverified personal names; the rest contain valid personal name headings with unverified uniform titles (see figure 10),

2. Obsolete main headings (14 occurrences). Fourteen personal name headings contain obsolete forms of names. They differ from the currently established headings in spelling, qualifier, or dates. Types of obsolete elements in the main heading include obsolete dates that have been updated or revised in current headings, missing or obsolete qualifiers, and obsolete form or spelling of personal names (see figure 11).

3. Obsolete subdivisions (13 occurrences). Thirteen personal name headings contain obsolete subdivisions, all involving topical/form subdivisions. Among these, 11 contain the defunct form subdivision Addresses, essays, lectures. Of the 2 remaining obsolete headings, 1 contains a subdivision which is no longer authorized and the other shows an obsolete form of subdivision (see figure 12).

4. Obsolete punctuation, capitalization, etc. (2 occurrences) (see figure 13).

\section{CoRporate Name HEadings}

INCORRECT HEADINGS

As shown in table 3 , a total of 39 incorrect 
600 Alba, Fernando Alvarez de Toledo, \$c duque de, \$d 1507-1782

(correct dates: \$d 1507-1582)

600 Abildgaard, Nocolai, $\$$ d 1743-1809 $\$ \mathrm{x}$ Journeys $\$ \mathrm{z}$ Italy $\$$ z Rome (correct first name: Nicolai)

600 Mark

(correct form: 600 Mark, Saint)

600 Meschberger, Dian Lugenbuehl, \$d 1858-1954

(correct main heading: 600 Lugenbuehl, Dian, \$d 1858-1954)

600 Marx, Karl, \$d 1818-1883 \$t Der 18. Brumaire des Louis Bonaparte

(correct uniform title: \$t Achtzehnte Brumaire des Louis Bonaparte)

Figure 6. Errors in Main Heading for Personal Name Headings.

600 French, Francis \$d 1791?-1850 \$x Family

(comma missing before $\$ \mathrm{~d}$ )

600 Macdonough, Thomas. \$d 1783-1825

(correct heading: comma instead of period before $\$ \mathrm{~d}$ )

Figure 7. Errors in Punctuation, Capitalization, etc. for Personal Name Headings.

600 Machiavelli, Niccolò, 1469-1527 \$x Influence

(subfield code $\$ \mathrm{~d}$ missing before dates)

600 Minakami, Tsutomu, \$b 1919- \$x Journeys \$z China

(correct subfield code for dates: $\$ \mathrm{~d} 1919-$ )

Figure 8. Errors in Coding for Personal Name Headings.

600 Tada, Joni Eareckson \$x Religious life

(subdivision \$x Religious life not authorized after personal name)

Figure 9. Error in the Subdivision for Personal Name Headings.

corporate name headings were identified. Types of errors in descending order by the number of occurrences, are:

1. Errors in coding (14 occurrences). Errors in coding constitute one of the two largest groups among incorrect corporate name headings. These errors appear in the form of incorrect or missing MARC codes. The majority (12) contain incorrect field tags (see figure 14). It appears that a fairly common mistake in tagging occurs among headings for denominations such as Lutheran Church, a topical heading (650) often incorrectly tagged as a corporate name heading (610). The remaining 2 headings show incorrect or missing subfield codes (see figure 14).

2. Errors in main headings (14 occurrences). The other largest group of incorrect corporate name headings, also a total of 14 , contains errors in the main heading. Kinds of errors include incorrect spelling, incorrect or missing qualifiers, incorrect form or wording of headings, incorrect language, and incorrect entry elements (see figure 15).

3. Errors in subdivisions (8 occurrences). Types of errors in subdivisions are improper use or incorrect combinations of topical/form subdivisions, incorrect wording or spelling of subdivisions, and geographic subdivisions not authorized under par- 
600 Forster, Albert, $\$ d$ 1902-

600 Mazzoni, Marcel H

600 Mann, Heinrich, \$d 1871-1950 \$t Eine Freundschaft (unverified uniform title)

Figure 10. Unverified Names in Main Headings for Personal Name Headings.

600 Altmann, Adolf, $\$ d 1879$ -

(current heading: 600 Altmann, Adolf, \$d 1879-1944)

600 Muhammad, \$d d. $632 \$ x$ Cult

(current heading: 600 Muḥammad, \$c Prophet, \$d d. $632 \$ x$ Cult)

600 Temple, Frederick, \$c Abp. of Canterbury, \$d 1821-1902

(current heading: 600 Temple, Frederick, \$d 1821-1902)

600 Zegeer, David A. \$q (David Abraham), \$d 1922-

(current form: 600 Zegeer, David Abraham, \$d 1922-)

Figure 11. Obsolete Main Headings for Personal Name Headings.

600 Aristophanes $\$ x$ Influence $\$ x$ Jonson

(further subdivision under $\$ x$ Influence by person no longer authorized)

600 Acquaviva d'Aragona, Giovan Francesco, \$d d. 1569. \$x Portraits, caricatures, etc.

(current subdivision: \$x Portraits)

Figure 12. Obsolete Subdivisions for Personal Name Headings.

600 Tennyson, Alfred Tennyson, $\$ \mathrm{c}$ baron, $\$ \mathrm{~d}$ 1809-1892

(current heading: \$c Baron capitalized according to AACR2R)

600 Millin, Sarah Gertrude (Liebson), \$d 1889-1968

(current heading: 600 Millin, Sarah Gertrude Liebson, \$d 1889-1968)

Figure 13. Obsolete Punctuation, Capitalization, etc. for Personal Name Headings.

ticular main headings (see figure 16).

4. Errors in punctuation, capitalization, etc. (3 occurrences). Errors occur in the form of missing or extraneous punctuation marks (see figure 17).

\section{Obsolete Headings}

As shown in table 4 , a total of 52 obsolete corporate name headings were identified. Types of obsolete elements, in descending order by the number of occurrences, are:

1. Unverified names (30 occurrences). The majority of unverifiable corporate name headings, 24 of the 30 $(80 \%)$, show a frequency of use of 1 .
The unverified elements occur in main headings, subheadings, or uniform titles in main headings (see figure 18).

2. Obsolete subdivisions (11 occurrences). Types of obsolete subdivisions include defunct form subdivisions (e.g., Addresses, essays, lectures; Collected works; or Yearbooks) subdivisions representing aerial maps, and obsolete form of geographic subdivisions (see figure 19).

3. Obsolete main headings (9 occurrences). Types of obsolete elements in main headings include missing 
610 Marriage law \$z Malawi

(correct field tag: 650)

610 Masai Mara Game Reserve

(correct field tag: 651)

610 Mennonites $\$ z$ United States $\$ x$ History

(correct field tag: 650)

Figure 14. Errors in Coding for Corporate Name Headings.

610 Alaska. \$b Department of Military and Veterans Affairs \$x Periodicals

(correct subheading: \$b Dept. of Military and Veterans Affairs)

610 Moviemento federativo democratico

(correct main heading: 610 Movimento federativo democratico)

610 Albatros D. (Fighter planes)

(correct qualifier: (Fighter plane))

610 Abadía del Sacromonte, Granada

(correct qualifier: (Granada, Spain))

610 Audley End

(missing qualifier: Audley End (England))

610 Training of Youth for Self-Employment (India) \$x Case studies

(correct main heading: 610 Training of Rural Youth for Self-Employment (India))

610 France. \$b Parliament (1946-)

(correct subheading: \$b Parlement (1946- ))

610 The Credit Mobilier of America

(correct heading: 610 Credit Mobilier of America)

Figure 15. Errors in Main Headings for Corporate Name Headings.

610 Adelphi Theatre (London, England) \$x Chronology

(correct heading: 610 Adelphi Theatre (London, England) \$x History \$x Chronology)

610 American Association of Nurserymen \$x Directories \$x Periodicals

(subdivision \$x Periodicals may not follow \$x Directories)

610 American Baptist Churches in the U.S.A. \$z Delaware \$x History (geographic subdivision not authorized)

Figure 16. Errors in Subdivisions for Corporate Name Headings.

qualifiers, obsolete form of qualifiers, obsolete uniform titles, obsolete entry elements, and obsolete spelling (see figure 20).

4. Obsolete coding ( 1 occurrence), One heading contains an obsolete subfield code, because the subheading under the corporate main heading has been changed to a geographic subdivision (see figure 21).

5. Obsolete punctuation, capitalization, etc. (1 occurrence). One heading contains obsolete punctuation for the qualifier (see figure 22). 
610 France. \$b Parlement (1946-) \$b Assemblée nationale \$x Elections (period (.) missing before $\$ \mathrm{~b}$ )

610 Tirumalai Tirupati Devasthanam (hyphen missing in Tirumalai-Tirupati)

Figure 17. Errors in Punctuation, Capitalization, etc. for Corporate Name Headings.

610 Career Opportunities Program

610 Enfield Arsenal

610 Manitoba. \$b Municipal Board

610 Mexico \$t Diario oficial de la federación \$x History (unverified uniform title)

Figure 18. Unverified Names for Corporate Name Headings.

610 Partai Nasional Indonesia \$x Addresses, essays, lectures (defunct subdivision: \$x Addresses, essays, lectures)

610 Michigan State University \$x Description \$x Aerial \$x Maps (current heading: 610 Michigan State University \$x Aerial views)

610 Catholic Church \$z Germany (West) \$z Bavaria \$x Clergy \$x Biography (current geographic subdivision: $\$ \mathrm{z}$ Germany $\$ \mathrm{z}$ Bavaria)

Figure 19. Obsolete Subdivisions for Corporate Name Headings.

\section{HEADINGS FOR MEETINGS}

The sample contains a total of 5 headings, all showing a frequency of use of 1 . Three of the headings are invalid, all involving the main heading.

\section{INCORRECT HEADINGS}

As shown in table 3 , only 1 incorrect heading for meetings was identified; it contains an extraneous date (see figure 23).

\section{ObSOLETE Headings}

As shown in table 4, only 2 obsolete headings for meetings were identified; they contain obsolete forms of qualifier, both lacking the additional geographic qualifier of a larger place required by AACR2R (see figure 24).

\section{UNIFORM TITLES}

\section{INCORRECT HEADINGS}

As shown in table 3, a total of 8 incorrect uniform title headings were identified.
Types of errors, in descending order by the number of occurrences, are:

1. Errors in coding (4 occurrences). Four headings contain errors in coding, which appear in the form of incorrect codes or missing codes (see figure 25).

2. Errors in main headings (3 occurrences). Errors in main headings occur in entry elements or qualifiers (see figure 26).

3. Error in the subdivision (1 occurrence). The error involves an incorrect form of a topical/form subdivision (see figure 27).

Obsolete Headings

As shown in table 4, a total of 13 obsolete uniform title headings were identified. Types of obsolete elements, in descending order by the number of occurrences, are:

1. Obsolete subdivisions (6 occurrences). All except one of the obsolete subdivisions involve the use of the defunct form subdivision: $A d-$ 
610 Thomas Road Baptist Church (current heading; 610 Thomas Road Baptist Church (Estill County, Ky.))

610 Manila. \$b Health Dept. \$x History (current main heading: 610 Manila (Philippines))

610 Cincinnati Bengals (Football club) (current qualifier: (Football team))

610 Freiburg i. B. \$b Universität. \$b Medizinische Fakultät (current heading: 610 Universität Freiburg im Breisgau. \$b Medizinische Fakultät)

The remaining obsolete main heading contains an old corporate name heading which, according to a note in the name authority record, has not been updated: 610 Auctiones A.G.

Figure 20. Obsolete Main Headings for Corporate Name Headings.

610 Freemasons. \$b Argentina

(current heading: 610 Freemasons $\$ z$ Argentina)

Figure 21. Obsolete Coding for Corporate Name Headings.

610 Texas. \$b Constitutional Convention, 1974

(current heading: 610 Texas. \$b Constitutional Convention (1974))

Figure 22. Obsolete Punctuation, Capitalization, etc. for Corporate Name Headings.

611 American Chess Congress (1857- ) \$n (6th : \$d 1889 : \$c New York, N.Y.) (correct heading: 611 American Chess Congress $\$ \mathrm{n}(6 \mathrm{th}: \$ \mathrm{~d} 1889$ : \$c New York, N.Y.)

Figure 23. Incorrect Headings for Meetings.

611 Asian International Trade Fair \$n (3rd : \$d 1972 : \$c Delhi) (current qualifier: \$c Delhi, India)

Figure 24. Obsolete Headings for Meetings.

630 Mothers' pensions $\$ \mathrm{z}$ Australia

(correct field tag: 650)

630 Puranas. Bhavisyapurāṇa

(subfield code $\$ \mathrm{p}$ missing before subheading Bhavisyapurāna)

Figure 25. Errors in Coding for Uniform Title Headings.

dresses, essays, lectures. The remaining heading represents an obsolete application of a subdivision (see figure 28).

2. Unverified uniform titles (5 occurrences). All 5 headings containing unverified uniform titles that do not have corresponding authority records show a frequency of use of 1 (see figure 29).

3. Obsolete main headings (2 occurrences). These differ from the currently established headings in spelling or in the qualifier (see figure 30 ). 
630 First epistle of Clement to the Corinthians

(correct main heading: 600 Clement I, Pope. \$t First epistle of Clement to the Corinthians)

630 Time (Chicago)

(correct main heading: 630 Time)

Figure 26. Errors in Main Headings for Uniform Title Headings.

630 Tripițaka. \$p Sūtrapitaka. \$p Buddhāvatamsakamahāvaipulyasūtra. \$p Gandavyūha \$x Paraphrases \$x Japanese

(correct subdivision: \$x Paraphrases, Japanese)

Figure 27. Error in the Subdivision for Uniform Title Headings.

630 Bible. \$1 English \$x Versions \$x Addresses, essays, lectures

(Defunct subdivision: \$x Addresses, essays, lectures)

630 Matsura no Miya monogatari \$x Translations, English

(Subdivision \$x Translations, English no longer used under individual works)

Figure 28. Obsolete Subdivisions for Uniform Title Headings.

630 Acta Sanctorum

630 The Advent (Anglo-Saxon lyrics)

Figure 29. Unverified Uniform Titles.

630 Tirez sur le pianiste (Motion picture)

(qualifier (Motion picture) no longer used)

630 Zoria (Lvov, Ukraine) \$x Indexes

(current spelling of geographic name in qualifier: (Liviv, Ukraine))

Figure 30. Obsolete Main Headings for Uniform Title Headings.

\section{TOPICAL HEADINGS}

\section{INCORRECT HEADINGS}

As shown in table 3, a total of 168 incorrect topical headings were identified. Types of errors, in descending order by the number of occurrences, are:

1. Errors in subdivisions (76 occurrences). Errors in subdivisions involve all types:

a. Geographic subdivision (39 occurrences). Errors in geographic subdivisions occur in application or form of geographic names (see figure 31).

b. Topical and form subdivision (32 occurrences). Errors in topical and form subdivisions occur in application or terminology (see figure 32). c. Chronological subdivision (5 occurrences). All 5 headings pertain to improper application of the chronological subdivisions (subfield y) (see figure 33).

2. Errors in main headings (45 occurrences). Errors in main headings occur as incorrect form, incorrect spelling, or incorrect entry elements (see figure 34).

3. Errors in coding (43 occurrences). Errors in coding include incorrect field tags or subfield codes and missing subfield codes (see figure 35 ).

4. Errors in punctuation, capitalization, etc. (4 occurrences). Errors in punctuation appear as incorrect or missing punctuation marks (see figure 36). 
650 Art metal-work, Medieval $\$$ z Scandinavia

(geographic subdivision not authorized under main heading)

650 Geology $\$ z$ Pacific Coast $\$ x$ Congresses

(correct form of subdivision: $\$ z$ Pacific Coast (U.S.))

650 Mylonite $\$ z$ Norway $\$ z$ Gong Region

(correct subdivision: $\$ z$ Norway $\$ z$ Grong Region)

Figure 31. Errors in Geographic Subdivisions for Topical Headings.

650 Arhats $\$ \mathrm{x}$ Art

(subdivision \$x Art not authorized for use under collective headings)

650 Bereavement $\$ x$ Personal narratives

(incorrect use of subdivision: \$x Personal narratives)

650 Happiness \$x Religious life \$x Christianity \$x Sermons (correct form of subdivision: \$x Religious aspects)

650 Inland navigation $\$ z$ England $\$ z$ Fens, The $\$ x$ Maps

(incorrect combination of 650 Inland navigation $\$ \mathrm{x}$ Maps; correct heading: 650 Nautical charts $\$ z$ England $\$ z$ Fens, The)

Figure 32. Errors in Topical or Form Subdivisions for Topical Headings.

650 Private libraries $\$ \mathrm{z}$ Hungary $\$ \mathrm{z}$ Budapest $\$ \mathrm{x}$ History $\$ \mathrm{y}$ 1400-1600

(chronological subdivision \$y 1400-1600 not established)

650 Authors, Gujarati \$y To 1500 \$ Biography

(main heading not subdivisible by $\$ y$ To 1500 )

650 Medicine \$y Medieval

(correct heading: 650 Medicine, Medieval)

Figure 33. Errors in Chronological Subdivisions for Topical Headings.

Obsolete Headings

As shown in table 4, a total of 277 obsolete topical headings were identified. Types of obsolete elements, in descending order by the number of occurrences, are:

1. Obsolete subdivisions (215 occurrences). Types of obsolete subdivisions include obsolete terminology or syntax and obsolete Main HeadingSubdivision or -Subdivision-Subdivision combinations. They involve all types of subdivisions:

a. Geographic subdivision (168 occurrences). Types of obsolete geographic subdivision include obsolete form of names, obsolete practice (e.g., direct subdivision where current policy requires indirect subdivision), and obsolete citation order (i.e., placement of the geographic subdivision within the string) (see figure 37). 
650 Arms transfer

(correct main heading: 650 Arms transfers)

650 Marketing surveys $\$ z$ United States $\$ \mathrm{x}$ Periodicals

(correct main heading: 650 Market surveys)

650 Trios (Piano, unspecified instrument, viola) $\$ \mathrm{x}$ Scores

(correct main heading: 650 Trios (Piano, viola, unspecified instrument))

650 Tumors in chidren $\$ \mathrm{x}$ Congresses

(correct main heading: 650 Tumors in children)

650 Military airlift \$z Washington National Airport \$x History

(correct main heading: 650 Airlift, Military)

Figure 34. Errors in Main Headings for Topical Headings.

650 Toppen, W. H.

(correct field tag: 600)

650 Carthusians $\$ x$ Spiritual life

(correct field tag: 610)

650 Aged $\$ z$ Religious life

(correct subfield code: \$x Religious life)

650 Aged \$z United States \$z States \$x Abuse of \$x Reporting

(correct subfield code: $\$ \mathrm{x}$ States)

650 Jewish-Arab relations, $1967-1973$

(correct heading: 650 Jewish-Arab relations \$y 1967-1973)

Figure 35. Errors in Coding for Topical Headings.

650 Medical microscopy,

(extraneous comma (,) at the end of heading)

650 Teachers \$x Supplementary employment \$z United States. \$x Statistics (extraneous period (.) before $\$ \mathrm{x}$ Statistics)

Figure 36. Errors in Punctuation, Capitalization, etc for Topical Headings.

b. Topical or form subdivision ( 45 occurrences). Types of obsolete topical or form subdivision include obsolete combinations, obsolete forms of subdivision, and defunct form subdivisions, such as Addresses, essays, lectures; Collected works; and Yearbooks (see figure 38).

c. Chronological subdivision (2 occurrences). The two obsolete chronological subdivisions involve obsolete forms of dates and previously open dates that have been closed (see figure 39).
2. Obsolete main headings (41 occurrences). Types of obsolete elements in main headings include terminology, form of main headings, and syn$\operatorname{tax}$ (see figure 40).

3. Unverified names (13 occurrences). Unverified names include geographic names in subdivisions and fictitious names in main headings (see figure 41).

4. Obsolete punctuation, capitalization, etc. (8 occurrences). Obsolete punctuation, capitalization, etc. occur in 
650 Literary landmarks \$z Russian S.F.S.R. \$z Leningrad \$x Maps (current subdivision: \$z Russia (Federation) \$z Saint Petersburg)

650 Education \$z Yugoslavia \$z Bosnia and Hercegovina \$x History (current subdivision: \$z Bosnia and Hercegovina)

650 Half-timbered buildings $\$ z$ Germany (West) \$z Westphalia $\$$ x Catalogs (current subdivision: $\$ \mathrm{z}$ Germany $\$ \mathrm{z}$ Westphalia)

650 Art \$z San Francisco \$x Catalogs (current subdivision: $\$ \mathrm{z}$ California $\$ \mathrm{z}$ San Francisco)

650 Occultism $\$ \mathrm{z}$ Tibet

(current subdivision: \$z China \$z Tibet)

650 Land use \$x Planning $\$ \mathrm{z}$ Great Britain (current heading: 650 Land use \$z Great Britain \$x Planning)

Figure 37. Obsolete Geographic Subdivisions for Topical Headings.

650 Special funds $\$ z$ Japan $\$ x$ Yearbooks (defunct subdivision: \$x Yearbooks)

650 Flight \$x Legends (obsolete use of subdivision \$x Legends following topical headings)

650 Actors \$z Japan \$x Portraits, etc. (current subdivision: $\$ \mathrm{x}$ Portraits)

650 Astronautics $\$ \mathrm{z}$ United States $\$ \mathrm{x}$ Moral and religious aspects (current subdivision: \$x Moral and ethical aspects)

650 Malaria \$x Complications and sequelae \$x Animal models (current heading: 650 Malaria \$x Complications \$x Animal models)

Figure 38. Obsolete Topical or Form Subdivision for Topical Headings.

650 French drama \$x Medieval \$x Translations into English (current subdivision: \$y To 1500)

650 Economic history \$y 1971- \$x Handbooks, manuals, etc. (current subdivision: \$y 1971-1990)

Figure 39. Obsolete Chronological Subdivisions for Topical Headings.

the use of parentheses, hyphen, and capital letters (see figure 42).

\section{Geographic Name Headings}

\section{INCORRECT HEADINGS}

As shown in table 3, a total of 57 incorrect geographic name headings were identified. Types of errors, in descending order by the number of occurrences, are:

1. Errors in main headings (23 occurrences). Errors appear in the form of incorrect or missing qualifiers in local place names, incorrect spelling, or incorrect form of headings (see figure 43).

2. Errors in subdivisions (23 occurrences). 
650 Children \$x Care and hygiene

(current heading: 650 Children $\$$. Health and hygiene or 650 Child care)

650 Australian aborigines $\$$ z Australia $\$$ z Tasmania (current main heading: 650 Tasmanian aborigines)

650 Agriculture, Primitive $\$ z$ China (current main heading: 650 Traditional farming)

650 Pest control, Integrated (current heading: 650 Pests $\$ x$ Integrated control)

650 Creativity in art (current main heading: 650 Creation (Literary, artistic, etc.))

650 Recruiting of employees $\$$ z Pakistan (current heading: 650 Employees \$x Recruiting \$z Pakistan)

Figure 40. Obsolete Main Headings for Topical Headings.

650 Desertification \$z Sudan \$z Umm Kaddada Region

(unverified name in subdivision: \$z Umm Kaddada)

650 Fishes \$z Louisiana \$z Delta National Wildlife Refuge (unverified name in subdivision: \$z Delta National Wildlife Refuge)

650 Mammals, Fossil \$z Iraq \$z Palegawra Cave (unverified name in subdivision: \$z Palegawra Cave)

650 Zippy (Cartoon character)

(unverified fictitious name heading)

Figure 41. Unverified Names for Topical Headings.

650 Election law \$z Germany, West

(current subdivision: \$z Germany (West))

650 Folk-songs, Italian \$x Texts

(current main heading: 650 Folksongs, Italian)

650 Agriculture $\$ \mathrm{z}$ France $\$ \mathrm{z}$ Caen region $\$ \mathrm{x}$ Maps

(current subdivisions: \$z France \$z Caen Region \$x Maps)

Figure 42. Obsolete Punctuation, Capitalization, etc. for Topical Headings.

a. Topical or form subdivision (16 occurrences). Errors occur in the form of improper or unauthorized combination of subdivisions with main headings or with other subdivisions and in incorrect terminology (see figure 44 ).

b. Chronological subdivision (5 occurrences). Types of errors include wrong dates and unauthorized use of subdivisions (see figure 45). c. Geographic subdivision (2 occurrences), Both incorrect geographic subdivisions involve application (see figure 46).

3. Errors in coding (8 occurrences). Errors include incorrect field tags and incorrect subfield codes (see figure 47).

4. Errors in punctuation, etc. (3 occurrences). Errors include incorrect punctuation and missing space (see figure 48). 
651 Arrowhead, Lake, Region (Calif.) \$x Maps

(correct main heading: 651 Arrowhead, Lake, Region (San Bernardino County, Calif. : Lake))

651 Aschersleben \$x Buildings, structures, etc.

(correct main heading: 651 Aschersleben (Germany : Landkreis))

651 Mexico, Valley of

(correct main heading: 651 Mexico, Valley of (Mexico))

651 Winhoek (Namibia) \$x Maps

(correct main heading: 651 Windhoek (Namibia))

651 Pacific Ocean Region \$x Foreign relations \$z Soviet Union

(correct main heading: 651 Pacific Area)

Figure 43. Errors in Main Headings for Geographic Name Headings.

651 Asia, Southeastern \$x History \$ Japanese occupation

(use of $\$ \mathrm{x}$ Japanese occupation not authorized)

651 Europe \$x Kings and rulers \$x History \$y 19th century

(subdivision \$x History may not follow \$x Kings and rulers)

651 Europe $\$ x$ Social conditions $\$ x$ History

(subdivision $\$ \mathrm{x}$ History may not follow $\$ \mathrm{x}$ Social conditions)

651 Toledo (Ohio) \$x Pictorial views

(correct subdivision: \$x Pictorial works)

Figure 44. Errors in Topical or Form Subdivision for Geographic Name Headings.

651 India \$x Politics and government \$y To 1000

(correct subdivision: \$y To 997)

651 Mediterranean Region \$x History \$y To 146 B.C.

(chronological subdivision \$y To 146 B.C. not established)

Figure 45. Errors in Chronological Subdivision for Geographic Name Headings.

651 Prague (Czechoslovakia) \$x Streets \$z Zlatá ulička

(name of street Zlatá ulĩcka not valid as geographic subdivision; also obsolete form of qualifier)

651 America \$x Discovery and exploration \$z Spain

(incorrect subdivision: \$z Spain) (correct subdivision: \$x Spanish)

Figure 46. Errors in Geographic Subdivision for Geographic Name Headings.

\section{Obsolete Headings}

As shown in table 4, a total of 142 obsolete geographic name headings were identified. Types of obsolete elements, in descending order by the number of occurrences, are:

1. Obsolete main headings (49 occur- rences). Obsolete elements occur in the forms of geographic names (approximately half involving the former Soviet republics) and in qualifiers (see figure 49).

2. Obsolete subdivisions (44 occurrences). 
651 Ferrocarril del Cobre (Cuba) \$x Maps

(correct field tag: 610)

651 Metz (France) \$x History $\$$ x Siege, 1870

(correct subfield code: \$y Siege, 1870)

651 Africa, East \$x Description and travel \$y 1981- \$z Guidebooks (correct subfield code: $\$ \mathrm{x}$ Guidebooks)

Figure 47. Errors in Coding for Geographic Name Headings.

651 Manti La Sal National Forest (Utah and Colo.) \$x Guidebooks

(correct main heading: 651 Manti-La Sal National Forest (Utah and Colo.))

651 Meredith, Lake Region (Tex.) \$x Maps

(correct main heading: 651 Meredith, Lake, Region (Tex.))

651 Turkey $\$ \mathrm{x}$ Foreign relations $\$ \mathrm{z}$ MogulEmpire

(correct subdivision: \$z Mogul Empire)

Figure 48. Errors in Punctuation, etc. for Geographic Name Headings.

651 Leningrad Region (R.S.F.S.R.) \$x Maps, Tourist

(current main heading: 651 Saint Petersburg Region (Russia))

651 Emilia-Romagna \$x Road maps

(current main heading: 651 Emilia-Romagna (Italy))

651 Maui \$x Maps

(current main heading; 651 Maui (Hawaii))

651 Santa Cruz, Argentine Republic (Province) \$x Maps

(current main heading: 651 Santa Cruz (Argentina : Province))

651 Anacostia, D.C. \$x Exhibitions

(current main heading: 651 Anacostia (Washington, D.C.))

Figure 49. Obsolete Main Headings for Geographic Name Headings.

a. Topical or form subdivision (34 occurrences). Types of obsolete elements include obsolete Main Heading-Subdivision and -Subdivision-Subdivision combinations, and obsolete terminology or syntax of subdivisions (see figure 50).

b. Chronological subdivision ( 5 occurrences). Obsolete elements include obsolete chronological subdivisions with open dates, obsolete application, and chronological subdivisions no longer authorized for use under the particular headings (see figure $51)$. c. Geographic subdivision (5 occurrences). Obsolete geographic subdivisions include both form of geographic names (all involving the former Soviet Republics) and application (see figure 52).

3. Unverified geographic names (43 occurrences). Thirty-five, or over $80 \%$, of the 43 headings containing unverified geographic names show a frequency of use of 1 (see figure 53).

4. Obsolete punctuation, capitalization, etc. (6 occurrences). Obsolete elements include pre-AACR2R punctuation for forms of qualifiers and obsolete capitalization (see figure 54). 
651 India \$x Nonalignment

(current heading: 650 Nonalignment $\$ z$ India)

651 Contra Costa County (Calif.) \$x Occupations \$x Periodicals (current heading: 650 Occupations $\$$ z Contra Costa County (Calif.) \$x Periodicals)

651 North Carolina \$x Description and travel \$y 1981- \$x Views (current heading: 651 North Carolina $\$ \mathrm{x}$ Pictorial works)

651 Hong Kong \$x Yearbooks (defunct subdivision: $\$ \mathrm{x}$ Yearbooks)

651 Torredembarra (Spain) \$x Description (current subdivision: \$x Description and travel)

Figure 50. Obsolete Topical or Form Subdivision for Geographic Name Headings.

651 Sicily (Italy) \$x History \$y 1870-

(current subdivision: \$y 1870-1945)

651 Germany (West) \$x Foreign relations \$y 1945-

(current heading: 651 Germany (West) \$x Foreign relations)

The following heading, with a high frequency of use of 258 , shows an obsolete open date that has been closed: 651 South Africa \$x Politics and government \$y 1978(current subdivision: \$y 1978-1989)

Figure 51. Obsolete Chronological Subdivision for Geographic Name Headings.

651 Middle East \$x Library resources \$z North America \$x Congresses

( $\$ \mathrm{x}$ Library resources no longer further subdivided by place)

651 Tamil Nadu (India) \$x Relations \$z Bengal \$x Congresses (current subdivision: $\$ \mathrm{z}$ India $\$ \mathrm{z}$ Bengal)

651 Asia \$x Study and teaching \$z Russian S.F.S.R. \$z Moscow (current subdivision: \$z Russia (Federation) \$z Moscow)

Figure 52. Obsolete Geographic Subdivision for Geographic Name Headings.

651 Belleville-sur-Meuse, France \$x Maps

651 Lake Manyara National Park (Tanzania) \$x Road maps

651 Norton, Eng. (Rural district) \$x Guidebooks

651 Mont Blanc Tunnel

Figure 53. Unverified Geographic Names.

651 Malakoff, France \$x Maps

(current form of qualifier: 651 Malakoff (France))

651 Korea \$x History \$y Japanese invasions, 1592-1598

(current subdivision: \$y Japanese Invasions, 1592-1598)

Figure 54. Obsolete Punctuation, Capitalization, etc. for Geographic Name Headings. 


\section{SUMMARY: FREQUENTLY OCCURRING ERrors and Obsolete Elements}

Among the invalid headings, certain types of errors and obsolete elements occur repeatedly. These are summarized and discussed below.

\section{ERRORS}

The most frequently occurring errors are found in main headings (35.62\%) and in subdivisions (35.62\%) (cf. table 3). Errors in MARC coding account for $23.86 \%$ of the incorrect headings. Mechanical errors in punctuation, capitalization, etc. are relatively few.

Kinds of errors among different types of headings, in descending order of occurrence, are:

- Personal name headings: main heading, mechanical errors, coding, and subdivision

- Corporate name headings: coding, main heading, subdivision, and mechanical errors

- Headings for meetings: main heading

- Headings for uniform titles: coding, main heading, and subdivision

- Topical headings: subdivision, main heading, coding, and mechanical errors

- Geographic name headings: main heading, subdivision, coding, and mechanical errors

In MARC coding, a common error is the use of the field tag 610 (corporate name heading) to code a topical heading, which should be assigned the code 650 . This occurs particularly frequently when a topical heading representing a Christian denomination or religious group, such as Lutheran Church or Mennonites, is assigned the field tag 610 instead of the correct tag 650 . On the other hand, religious orders, such as Franciscans, which should be coded 610, are sometimes tagged 650. Errors in subfield coding consist of missing or misapplied codes. One recurring error was found in the combination $\$ z$ United States $\$ z$ States, where the correct subfield code for States is subfield $\mathrm{x}$.

Errors in main headings are mostly typographical in nature, such as misspelled words or alternate word forms or, in the case of personal name headings, incorrect numbers in dates.

The most common errors in subdivisions involve the application of topi$\mathrm{cal} /$ form subdivisions and geographic subdivisions. One possible explanation is that most of these subdivisions are free-floating, and the headings were not synthesized properly.

Among topical/form subdivisions (subfield $x$ ), a common type of error is the improper use of the subdivision \$x History as a further subdivision under certain topical subdivisions. LC policy indicates that a number of subdivisions "that are historical in nature" or "that have traditionally been regarded as being explicitly or implicitly historical" (Library of Congress 1984-, H1647, 3) should not be fur ther subdivided by $\$ \mathbf{x}$ History. These include:

\section{- \$x Antiquities \\ - \$x Courts and courtiers \\ - \$x Foreign relations \\ - \$x Kings and rulers \\ - \$x Military policy \\ - \$x Social conditions}

Thus, combinations such as $\$ x$ Courts and courtiers $\$ x$ History and $\$ x$ Social conditions $\$ x$ History are not valid. A complete list of these subdivisions appears in Library of Congress (1984-, H1647, 5).

Relatively few errors were found in chronological subdivisions, possibly because few of them are free-floating. Almost all period subdivisions are enumerated in LCSH. Where errors do occur, they usually involve typographical errors or improper use of a chronological subdivision under a topical or geographic name heading where the subdivision is not authorized or has not been established.

Geographical subdivisions are used most frequently under topical headings. Errors occur when a heading is subdivided by place where the geographic subdivision is not authorized or when a heading is subdivided directly where indirect subdivision is required.

Overall, errors in punctuation, capitalization, etc. are relatively few, and con- 
sist mainly of extraneous or missing punctuation marks and incorrect capitalization or spacing. There is no clear pattern of recurring errors.

\section{OBSOLETE ELEMENTS}

Among obsolete headings, the most common obsolete elements are found in subdivisions $(51.7 \%$ ) (cf. table 4 ). The second largest group of obsolete headings contains unverifiable names $(24.15 \%)$, particularly personal and geographic names. The third group of obsolete headings contains previous forms of main headings $(20.93 \%)$. There are relatively few obsolete mechanical elements (3.04\%), and only one instance of obsolete MARC coding was found $(0.18 \%)$.

Kinds of obsolete elements among different types of headings, in descending order of occurrence, are:

- Personal name headings: unverified names, main heading, subdivision, and mechanical elements

- Corporate name headings: unverified names, subdivision, main heading, coding, and mechanical elements

- Headings for meetings: main heading

- Headings for uniform titles: subdivision, unverified names, and main heading

- Topical headings: subdivision, main heading, unverified names, and mechanical elements

- Geographic name headings: main heading, subdivision, unverified names, and mechanical elements

LCSH is a dynamic system that changes continuously. When a heading is revised, it is the policy of $\mathrm{LC}$ and most other libraries to update all headings in the bibliographic records that are affected by the change. It appears that in some cases the required changes have not been made or are in the process of being made. At any particular time, it is to be expected that the database would contain obsolete headings. The sample used in this study represents a snapshot of the LC MARC database at a specific point in time. As a result, some of the obsolete elements might be recurring phenomena, while others might not be typical. The following discussion summarizes some of the more commonly recurring obsolete elements.

In recent years, many inverted topical headings such as Impersonators, Female have been converted to natural word order. The study sample contains a fair number of headings that have not been updated to agree with the current form. A large proportion of obsolete main headings involve the qualifier for name headings, including personal, corporate, and particularly geographic names. In many cases, the different form or addition of the qualifier is due to the changes in the descriptive cataloging rules in AACR2R. For geographic names of local places, the obsolete headings often lack the qualifiers in the form of the larger geographic entities as required by $A A C R 2 R$ and revised subject cataloging policies. This addition of the name of a larger geographic entity also affects corporate name headings and headings for meetings qualified by place.

In the sample used in this study, the obsolete forms of many geographic names used in both main headings and in geographic subdivisions were due to the political changes occurring in the former Soviet Union, the former East Germany and West Germany, and eastern European countries such as Yugoslavia and the former Czechoslovakia. These changes necessitated revision of the forms of the names. One possible reason for the large number of such headings identified here is the fact that the sample headings were generated shortly after the many changes mentioned above took place, and LC was in the process of revising headings relat. ing to these places.

In the case of personal names, many of the headings lack the death dates that have been added since the headings were first established.

Although form subdivisions such as Addresses, essays, lectures; Collected works; and Yearbooks were declared defunct a few years ago, many headings, particularly those with low frequency of use, still carry these subdivisions. One explanation could be the lack of monitoring in retrospective conversion.

Since the Future of Subdivisions Conference was held in 1991, LC has em- 
barked on a rather extensive review of free-floating subdivisions for the purpose of simplification. Many of the free-floating topical subdivisions have been converted to topical main headings, and a large number of topical/form subdivisions have been eliminated, combined, or consolidated with other subdivisions representing similar concepts. For example, the previously authorized subdivisions Portraits, caricatures, etc. and Portraits, etc. have been replaced by Portraits. In an effort to update existing headings, some headings with these obsolete or defunct subdivisions were probably not captured due to the fact that LC's automated system does not yet have the global change capability.

The most common type of obsolete chronological subdivision occurs in headings carrying an open date that has been closed in current usage. When new historical periods are established under headings, particularly headings relating to history, the previous periods are closed with an ending date, and existing headings with an open date require updating with the addition of the closing date.

In geographic subdivision, a fairly common type of obsolete element is the direct geographic subdivision involving local places, for which current policy requires indirect subdivision. In addition to the changed geographic names mentioned above, another recurring obsolete element involves the use of previously authorized forms of names in indirect subdivision, particularly in the case of the former Yugoslavia, Czechoslovakia, and East and West Germany. For example, while Germany (East) and Germany (West) are valid main headings and geographic subdivisions per se, in indirect subdivision involving local places in either Germany, the current form of the intervening geographic subdivision is Germany (e.g., \$z Germany \$z Munich not $\$ z$ Germany (West) \$z Munich).

Nearly one-fourth of all obsolete headings contain unverified names. As explained in the section on types of errors and obsolescence, while some of these headings may be valid according to current rules and policies, they cannot be used as authority for validation purposes. Over $80 \%$ of these headings show a frequency of use of 1 (Chan and VizineGoetz 1996). Many of these probably have corresponding name authority records in the card file at LC, which have not been converted into MARC records. When the names involved are needed for future cataloging, it is reasonable to expect that name authority records will be established and included in the NAMES file.

\section{CoNCLUSION}

The purpose of this research project was to collect and analyze data regarding assigned subject headings, which could help improve the quality and efficiency in subject authority control. Although errors occur at a relatively low rate, an understanding of the nature of errors and obsolete elements in assigned subject headings and of their patterns of occurrence and preponderance might be helpful in efforts to develop or enhance automatic error correction mechanisms. Errors in mechanics (i.e., punctuation, capitalization, etc.) and in terminology or grammatical forms of main headings as well as enumerated subdivisions lend themselves to automatic correction. Likewise, obsolete elements that are predictable are also amenable to automatic updating. Correction and updating can be effected by matching assigned headings against those in $L C S H$ and the name authority file. One exception is names used in subject headings that do not have corresponding name authority records. These include many personal and corporate names as well as some jurisdictional geographic names. They occur pervasively among headings with low frequencies of use, particularly those with a frequency of 1 or 2 .

Currently, correcting errors in freefloating subdivisions both in terminology and in application requires human intervention. The proposed subject validation file based on frequency of use and with complete strings and high rate of accuracy (Chan and Vizine-Goetz 1997) could help to reduce the number of cases of subdivision usage requiring human review. Even 
in cases requiring manual validation, data gathered in this study could serve to alert subject authority control personnel to frequently occurring errors and obsolete elements.

The results of this study might also be useful for those engaged in the training of subject catalogers. Instructors of subject cataloging might also find the data helpful. Being aware of the nature and patterns of errors is a step toward improving quality in subject heading assignment. In original cataloging, it is a common practice for catalogers to examine and use headings that have been assigned to existing records for items on similar subjects. Indiscriminate use of assigned heading strings might result in perpetuating errors. The data compiled in this study provide a statistical measurement of re-usability based on the number of postings for each heading as a gauge of accuracy and currency among existing headings.

\section{FURTHER RESEARCH}

The findings from this study lead us to suggest the following areas for further research:

1. It would be interesting to determine whether any correlation exists between the length of the subject heading string and the probability of error. The question is whether the complex syntax of headings with multiple subdivisions lend themselves to errors.

2. One finding in this study that warrants further investigation is the large number of headings that were assigned only once each. The $1 \%$ sample of 14,503 headings with a frequency of use of one in the initial sample database translates into over $1,450,300$ headings in the full bibliographic file. Even with the exclusion of approximately 240,000 invalid headings based on the $16.45 \%$ error and obsolescence rate (Chan and Vizine-Goetz, 1997), there are still over 1.2 million headings that have been used only once each. This phenomenon poses the questions of what effects the large number of unique headings has on browsing and re- trieval, particularly in terms of recall; and what its implications are for subject authority control. In terms of recall, it means that using these headings as search terms in retrieval will result in only one hit each. In browsing, the question is, What problems does the large number of headings create in both display and in identify. ing specific headings? With regard to authority control, it means that over one million authority records would be required to maintain control over headings that have been used only once. Since these headings affect only a small percentage of bibliographic records, the question is one of cost-effectiveness. It is recommended that a further investigation be carried out with focus on headings with a frequency of use of 1 , analyzing their patterns and composition, i.e., the percentage of newly established headings among them, their lengths, specificity, use of free-floating subdivisions, and their effect on display, retrieval, and subject authority control.

\section{Works CITED}

Anglo-American Cataloguing Rules. 1988. 2d ed., 1988 rev. Prepared under the direction of the Joint Steering Committee for Revision of AACR, a committee of: the American Library Association, the Australian Committee on Cataloguing, the British Library, the Canadian Committee on Cataloguing, the Library Association, Library of Congress, ed. Michael Gorman and Paul W. Winkler. Chicago: American Library Association.

Chan, Lois Mai, and Diane Vizine-Goetz. 1996. Feasibility of a computer-generated subject validation file based on frequency of occurrence of assigned Library of Congress Subject Headings: Phase II, nature and patterns of invalid headings. In Annual review of OCLC research, 1996. Dublin, Ohio: OCLC.

1997. Feasibility of a computer-generated subject validation file based on frequency of occurrence of assigned Library of Congress Subject Headings: Phase I, statistical analysis. Report on a research project sponsored by OCLC, Dublin, Ohio (submitted January 6, 1997). 
Drabenstott, Karen Markey, and Diane Vizine-Goetz. 1994. Using subject headings for online retrieval: Theory, practice, and potential. San Diego, Calif.: Academic Press.

Frost, Carolyn O. and Bonnie A. Dede. 1988. Subject heading compatibility between LCSH and catalog files of a large research library: A suggested model for analysis. Information technology \& libraries 7(3): 288-99.

Library of Congress. 1910/1914 . Library of Congress subject headings. Washington, D.C,: Cataloging Distribution Service, Library of Congress.

_- 1984-. Subject cataloging manual: Subject headings. Washington, D.C.: Library of Congress.

1989-. Free-floating subdivisions: An alphabetical index. Washington, D.C.: Cataloging Distribution Service, Library of Congress.

1991. Revised Library of Congress subject headings: Cross-references from former to current subject headings, compiled from the online subject authority file of the Library of Congress, 1st ed. Washington, D.C.: Cataloging Distribution Service, Li- brary of Congress.

Ludy, Lorene E. 1985. OSU libraries' use of Library of Congress Subject Authority File. Information technology o libraries 4: 155-60.

Subject Subdivisions Conference. 1992. The future of subdivisions in the Library of Congress subject headings system: Report from the Subject Subdivisions Conference, ed. Martha O'Hara Conway. Washington, D.C.: Library of Congress, Cataloging Distribution Service.

Svenonius, Elaine, and Dorothy McGarry. 1993. Objectivity in evaluating subject heading assignment. Cataloging \& classification quarterly 16(2):5-40.

USMARC format for authority data, including guidelines for content designation. 1987. Prepared by Network Development and MARC Standards Office. Washington, D.C.: Cataloging Distribution Service, Library of Congress.

USMARC format for bibliographic data, including guidelines for content designation. 1988. Prepared by Network Development and MARC Standards Office. Washington, D.C.: Cataloging Distribution Service, Library of Congress. 